\title{
High Maternal Serum Estradiol in First Trimester of Multiple Pregnancy Contributes to Small for Gestational Age via DNMT1-Mediated CDKN1C Upregulation
}

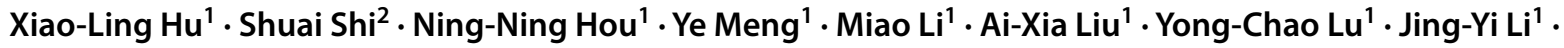 \\ Jian-Zhong Sheng ${ }^{2} \cdot$ Yi-Min Zhu ${ }^{1,3}$ (i) $\cdot$ He-Feng Huang ${ }^{1,3}$ (i)
}

Received: 30 March 2021 / Accepted: 4 September 2021 / Published online: 27 September 2021

(c) The Author(s) 2021

\begin{abstract}
High maternal serum estradiol $\left(\mathrm{E}_{2}\right)$ levels in the first trimester of pregnancy are associated with a high incidence of low birth weight (LBW) and small for gestational age (SGA). This study aimed to investigate the effect of first-trimester high maternal serum $\mathrm{E}_{2}$ levels on fetal growth and the underlying mechanisms in multiple pregnancies. Maternal serum $\mathrm{E}_{2}$ levels of women at 8 weeks of gestation were measured. The expression levels of imprinted genes and DNMT1 were determined by RT-qPCR, and $K v D M R 1$ methylation in embryo tissue, placenta, and newborn cord blood samples was examined by bisulfite sequencing PCR. The effect of $\mathrm{E}_{2}$ on CDKNIC expression was investigated in HTR8 cells. The incidence of SGA was significantly higher in multiple pregnancies reduced to singleton than that in primary singleton pregnancies $(11.4 \%$ vs. $2.9 \%)(P<0.01)$ and multiple pregnancies reduced to twins than primary twins $(38.5 \%$ vs. $27.3 \%)(P<0.01)$. The maternal serum $\mathrm{E}_{2}$ level at 8 weeks of gestation increased with the number of fetuses and was negatively correlated with offspring birth weight. CDKNIC and DNMTI expression was significantly upregulated in embryo tissue, placenta, and cord blood from multiple pregnancies. Furthermore, there was a positive correlation between $C D K N I C$ mRNA expression and $K v D M R I$ methylation levels. In HTR8 cells, DNMT1 mediated the estrogen-induced upregulation of $C D K N I C$, which might contribute to SGA. To minimize the risks of LBW and SGA, our findings suggest that abnormally high maternal serum $\mathrm{E}_{2}$ levels should be avoided during the first trimester of multiple pregnancies from assisted reproductive technology (ART).
\end{abstract}

Keywords Estradiol $\cdot$ Low birth weight $\cdot$ Small for gestational age $\cdot$ CDKN1C $\cdot$ Estrogen response elements

\section{Background}

Yi-Min Zhu

zhuyim@zju.edu.cn

$\triangle$ He-Feng Huang

hhf57@zju.edu.cn

1 Department of Reproductive Endocrinology, Women's Hospital, School of Medicine, Zhejiang University, 1 Xueshi Rd, Hangzhou 310006, Zhejiang, China

2 Department of Pathology and Pathophysiology, School of Medicine, Zhejiang University, Hangzhou 310058, Zhejiang, China

3 The Key Laboratory of Reproductive Genetics, Ministry of Education (Zhejiang University), Hangzhou 310006, China

Studies from diverse human cohorts and animal models have demonstrated that low birth weight (LBW) is a great risk for developing future adult chronic diseases $[1,2]$. Indeed, the maternal intrauterine environment plays a critical role in fetal development and growth. However, the mechanisms by which an adverse intrauterine environment affects fetal growth are still largely unknown.

A multiple gestation pregnancy is a common iatrogenic outcome of assisted reproductive technology (ART) mainly due to ovarian hyperstimulation. The frequency of multiple births with in vitro fertilization (IVF) ranges from 25 to $50 \%$ [3]. Multiple gestation pregnancies have an increased risk of LBW, especially when more than two fetuses are present [4-6]. It has been proposed that the reduced intrauterine growth of fetuses results from the constraints imposed by uterine size and a restricted ability of the placenta to support 
the nutrients required for fetuses during late gestation [5]. However, the procedure of fetal reduction in early gestation cannot eliminate all the detrimental effects of multiple gestations on the remaining fetuses. Our study showed that multiple pregnancies reduced to twins after ART treatment were still associated with a higher incidence of LBW and small for gestational age (SGA) than primary twin pregnancies. Moreover, the birth weights of singleton pregnancies from reduction were significantly lower than those of primary singleton pregnancies. Epidemiological studies of different cohorts showed that LBW was associated with adverse health outcomes, such as perinatal mortality and childhood neurologic diseases [7, 8]. Furthermore, newborns of LBW have a higher incidence of hypertension, type 2 diabetes, stroke, and coronary artery disease in later adult life [7, 9].

Although safety concerns in the first trimester of multiple pregnancies in ART are an issue, the mechanisms underlying LBW have not been well studied. The dramatic increase in estradiol $\left(E_{2}\right)$ in pregnant women may influence placental function and fetal development and play an important role in the development of numerous human diseases $[10,11]$. A study in rats has demonstrated that estrogenic exposure during maternal pregnancy increases the risk of breast cancer in offspring of multiple generations [12]. Our previous study found that a high maternal $\mathrm{E}_{2}$ environment in the first trimester was correlated with increased risks of LBW and SGA [13]. Thus, we propose that fetuses of the first trimester of multiple pregnancies exposed to an excessive $\mathrm{E}_{2}$ intrauterine environment may have a higher risk of LBW and SGA.

The epigenome is most susceptible to perturbation in early development $[14,15]$. The adverse effects of abnormal intrauterine exposure on fetuses may lead to epigenetic dysregulation. DNA methylation is one of the best-characterized epigenetic modifications. Abnormal DNA methylation is associated with many diseases $[12,16,17]$. DNA methyltransferase 1 (DNMT1) is the major DNMT for the maintenance of methylation and catalyzes DNA methylation by transferring a methyl group from the donor S-adenosyl methionine to the fifth carbon of cytosine [16]. Ample evidence has revealed that $D N M T 1$ overexpression contributes to hypermethylation associated with human disease $[16,18$, 19]. In cancer cells, DNMT1 overexpression might cause abnormal hypermethylation [20].

Genomic imprinting is an epigenetic phenomenon that results in monoallelic expression of certain genes in a parent-of-origin-dependent manner. Imprinted genes play important roles in the control of fetal growth and development [21]. CDKNIC is one of the best-studied imprinted genes that encodes a cyclin-dependent kinase inhibitor known to negatively regulate cellular proliferation and differentiation [22]. KvDMRI methylation on the maternal chromosome is proposed to activate $C D K N 1 C$, whereas demethylation of $K v D M R 1$ may cause $C D K N 1 C$ silencing
[23-25]. CDKN1C overexpression is one of the causes of Silver-Russell syndrome (SRS), a heterogeneous disorder characterized by severe intrauterine and postnatal growth retardation [26]. In contrast, aberrant CDKNIC silencing is associated with Beckwith-Wiedemann syndrome (BWS), which exhibits a loss of methylation (LOM) at the maternal $K v D M R 1$ imprinting control region [24, 27].

In the present study, we examined the expression levels of imprinted genes in embryo tissue from multiple and singleton gestation. We further examined the expression of imprinted $C D K N I C$ in neonatal umbilical cord blood (UCB) and placenta. We also investigated changes in CDKNIC expression in HTR8 cells treated with different $\mathrm{E}_{2}$ concentrations and the underlying mechanisms by which the dramatic increase of $E_{2}$ levels in pregnant women adversely affects fetal development and growth during the first trimester of multiple pregnancies.

\section{Materials and Methods}

\section{Subjects and Tissues}

This study was a retrospective study on patients that underwent ART from January 2010 to June 2014 at the Assisted Reproductive Unit of the Women's Hospital, School of Medicine, Zhejiang University (Hangzhou, China). Written informed consent was obtained from all patients who provided samples, and the study protocol was approved by the Ethics Committee of the Women's Hospital, School of Medicine, Zhejiang University. The inclusion criteria consisted of the selective reduction of one or more gestational sacs or embryos to singletons or twins before the 12th week of gestation. Patients with obstetric complications (e.g., gestational diabetes mellitus, hypertension, and placenta previa) or parents who consumed alcohol or smoked during pregnancy were excluded from this study. The control group included assisted reproduction patients with primary singletons or twins during the same period. Primary singletons were matched by a stratified random selection. In particular, the primary singletons chosen for the control group shared a similar maternal age, sex ratio, and gestational age to the reduced singletons. Analyses were restricted to pregnancies in which the duration of gestation was 28 weeks or longer. All pregnancies were confirmed by transvaginal ultrasonography. SGA was defined as a birth weight below the 10th percentile for the gestational age at delivery.

Multifetal pregnancy reduction (MFPR) was performed as previously described [28]. MFPR was performed early in pregnancy (about 8 weeks). Under ultrasound guidance, a 17-gauge needle was inserted through the vaginal wall into the chosen sac. Suction was applied, and all the embryonic parts were aspirated. The same technique was used for 
additional embryos, as needed. Maternal peripheral blood samples were obtained before MFPR at 8 weeks of gestation. UCB and placenta tissues of newborns from twins were collected at birth.

In total, 195 maternal serum samples were collected, 77 aspirated embryo tissues were collected from MFPR, and 29 embryo tissues of singleton pregnancies were collected from elective terminations of unintended normal pregnancies as controls. Mononuclear cells from UCB (UCBMNC) were separated using density gradient centrifugation and stored at $-80^{\circ} \mathrm{C}$, as previously described [29]. All tissue samples were collected immediately after surgical removal and were snap-frozen in liquid nitrogen.

\section{Measurement of Estradiol}

Maternal serum $\mathrm{E}_{2}$ levels were measured using electrochemiluminescence (Hoffman-La Roche, Mannheim, USA). The detection limit of for $\mathrm{E}_{2}$ was $18.4 \mathrm{pmol} / \mathrm{L}$, and the $\mathrm{CV} \%$ was 2.4-4.6\%.

\section{Cell Culture}

The HTR8/SVneo (HTR8) cell line was derived from a human first-trimester placenta explant immortalized by SV40 large T antigen [30]. The cells were cultured at $37^{\circ} \mathrm{C}$ with a 5\% $\mathrm{CO}_{2}$ atmosphere in phenol red-free PRMI 1640 medium (Gibco, Invitrogen, NY, USA) containing 10\% fetal bovine serum (FBS), $100 \mathrm{IU} / \mathrm{mL}$ penicillin, and $100 \mu \mathrm{g} / \mathrm{mL}$ streptomycin. For steroid starvation, cells were cultured in phenol-free PRMI 1640 containing 5\% charcoal-stripped FBS (Sigma, St. Louis, MO, USA).

\section{Total RNA Extraction and Real-time Quantitative RT-PCR (qRT-PCR)}

Total RNA was isolated from tissue samples or cells using Trizol reagent (Takara, Dalian, China). cDNA was synthesized using the PrimeScript ${ }^{\mathrm{TM}} \mathrm{RT}$ reagent Kit (Takara). qRTPCR was carried out with an ABI Prism 7900HT (Applied Biosystems, Foster City, CA, USA) using SYBR ${ }^{\circledR}$ Premix Ex TaqTM (Takara). The relative gene expression was normalized to glyceraldehyde-3-phosphate dehydrogenase $(G A P D H)$, as previously described [31]. The primers used in this study are listed in Supplemental Table 1.

\section{Methylation-Specific PCR (MSP)}

Genomic DNA was extracted from tissue samples or cells using a standard phenol-chloroform extraction method and modified with sodium bisulfite using the EpiTect®Bisulfite Kit (Qiagen, USA). DNA from peripheral blood mononuclear cells treated with SssI methyltransferase (New England
Biolabs, Beverly, MA, USA) was used as a positive control for methylated alleles. The methylation-specific primers for KvDMRI are listed in Supplemental Table 2.

\section{Bisulfite Sequencing PCR}

Bisulfite sequencing was performed using specific tissue samples and cells. The primers used for bisulfite sequencing of the KvDMRI fragment are listed in Supplemental Table 3. The amplified area contained $28 \mathrm{CpG}$ sites. Amplified PCR products were purified using a gel extraction kit (Takara) and ligated into the pMD19-T plasmid using the TA-cloning system (Takara). The sequences were analyzed using 3730 DNA Analyzer polymers (Applied Biosystems, Carlsbad, CA).

\section{$E_{2}$ and ICI182780 Treatment of HTR8 Cells}

$\mathrm{E}_{2}$ (Roche, Basel, Switzerland) and the estrogen receptor inhibitor ICI1 82780 (Sigma, St. Louis, MO, USA) were dissolved in dimethyl sulfoxide (DMSO, Sigma). HTR8 cells were seeded in 6-well plates in $2 \mathrm{~mL}$ of culture medium. Cells were treated with $0,10^{-9}, 10^{-8}$, or $10^{-7} \mathrm{M} \mathrm{E}_{2}$ for $24 \mathrm{~h}$. To investigate the effects of estrogen, cells were pretreated with $10^{-5} \mathrm{M}$ ICI 182780 for $4 \mathrm{~h}$ followed by stimulation with $10^{-7} \mathrm{M} \mathrm{E}_{2}$ for $24 \mathrm{~h}$.

\section{Gene Silencing with DNMT1 Small Interfering RNAs (siRNAs)}

For DNMT1 gene silencing, HTR8 cells were transiently transfected with DNMT1-specific siRNAs (Sigma) using Lipofectamine $^{\mathrm{TM}} 2000$ (Invitrogen, Carlsbad, CA), according to the manufacturer's instructions. Scrambled siRNA was used as a control. The knockdown efficiency was confirmed by qRT-PCR and western blotting.

\section{Western Blotting}

Western blot analysis was performed as previously described [32]. Briefly, proteins were separated by SDS-PAGE, transferred to nitrocellulose membranes, and exposed to a rabbit anti-DNMT1 antibody (1:800; Santa Cruz Biotechnology, Santa Cruz, CA) for $2 \mathrm{~h}$. The blots were incubated with a horseradish peroxidase-linked antirabbit IgG (1:5000; KPL, Maryland, USA) for $1 \mathrm{~h}$ at room temperature, and the specific protein band was visualized using the Licor Odyssey Infrared Imaging System (Licor, Lincoln, North Carolina, USA). 


\section{Plasmid Construction and Luciferase Reporter Assay}

The human DNMT1 promoter region ( -2493 to $-1 \mathrm{bp})$ was inserted into the pGL3-basic plasmid (Promega, Madison, WI, USA), resulting in the DNMT1 promoter-firefly luciferase reporter plasmid DNMT1-luc. The construct was verified by sequencing. HTR8 cells were co-transfected with DNMT1-luc and the Renilla luciferase plasmid pRLTK (Promega, Southampton, UK), which served as an internal transfection control. Transfection was performed using Fugene-HP (Roche, Basel, Switzerland), as per the manufacturer's instructions. The transfected cells were treated with $10^{-7} \mathrm{M} \mathrm{E}_{2}$ for $24 \mathrm{~h}$, and luciferase activity was measured using the Dual-Luciferase Reporter Assay System (Promega). Firefly luciferase was normalized to Renilla luciferase activity.

\section{Chromatin Immunoprecipitation (ChIP) Analysis}

ChIP experiments were performed as previously described with minor modifications [33]. Briefly, cells were crosslinked with $1 \%$ formaldehyde for $10 \mathrm{~min}$ at $37^{\circ} \mathrm{C}$, and the reaction stopped by the addition of glycine to a final concentration of $0.125 \mathrm{M}$. Lysates were sonicated on ice to shear the DNA to $200-800$ bp fragments. ChIP was performed with a ChIP assay kit (Millipore, Billerica, MA, USA), according to the manufacturer's instructions. The estrogen receptor $\alpha(\mathrm{ER} \alpha)$ antibody was obtained from Upstate (Millipore). The DNMT1 primers used for PCR are listed in Supplemental Table 4.

\section{Statistical Analysis}

Data are presented as the mean \pm standard error (SE). The two-tailed student's $t$-test or ANOVA was used to evaluate the statistical significance of continuous parametric data. The chi-square test was used to compare categorical data. All statistical analyses were performed using SPSS 23.0 software. Statistical significance was defined as $P<0.05$.

\section{Results}

\section{The Effect of First-Trimester Multiple Pregnancies on Birth Weight}

Information for all patients who underwent reduction was available. There were 105 singleton deliveries with selective reduction ( $<12$ weeks), 217 twin deliveries after selective reduction, 210 primary singleton births, and 864 primary twins without spontaneous or selective reduction for analysis. The mean birth weight in patients whose fetuses were reduced to singletons or twins was significantly lower than that of their corresponding controls $(3226.71 \pm 513.96 \mathrm{~g}$ vs. $3378.19 \pm 473.32 \mathrm{~g}(P<0.01)$ and $2428.80 \pm 485.64$ g vs. $2495.31 \pm 520.06 \mathrm{~g}(P<0.05)$, respectively). Fetus birth weights could also be affected by the gestational age at delivery. To further elucidate this issue, we analyzed the proportion of SGA infants. The incidence of SGA in multiple pregnancies reduced to singletons $(11.4 \%, 12 / 105)$ was significantly higher than that to primary singleton pregnancies $(2.9 \%, 6 / 210)(P<0.01)$. In addition, SGA in multiple pregnancies reduced to twins $(38.5 \%, 167 / 434)$ was significantly higher than that with primary twin pregnancies $(27.3 \%, 472 / 1728)(P<0.01)$.

\section{Maternal Serum $\mathrm{E}_{\mathbf{2}}$ Levels were Significantly Elevated with Increasing Number of Fetuses}

We analyzed maternal serum $\mathrm{E}_{2}$ levels at 8 weeks of gestation $(n=195)$, including 82 singleton conceptions, 45 twin conceptions, 58 triplet conceptions, and ten quadruplet conceptions. The results showed that maternal serum $\mathrm{E}_{2}$ levels were significantly elevated with an increasing number of fetuses. The mean serum $\mathrm{E}_{2}$ concentrations were $10,322.79$ $\pm 701.32 \mathrm{pmol} / \mathrm{L}$ for twin conceptions, $18,883.01 \pm 8321.94$ $\mathrm{pmol} / \mathrm{L}$ for triplet conceptions, and 31,794.10 \pm 6413.26 $\mathrm{pmol} / \mathrm{L}$ for quadruplet conceptions, which were all significantly higher than that of singleton pregnancies (7240.09 $\pm 465.48 \mathrm{pmol} / \mathrm{L}, P<0.01)$. Furthermore, there were significant differences in $\mathrm{E}_{2}$ levels among the four groups $(P<$ 0.01) (Fig. 1A).

\section{The Association between Maternal Serum $\mathrm{E}_{2}$ Levels of Multiple Pregnancies at 8 Weeks Gestation and Offspring Birth Weight}

We analyzed the correlation between maternal serum $\mathrm{E}_{2}$ levels of multiple pregnancies at 8 weeks gestation and the birth weights of pregnancies reduced to twins. The analysis showed that maternal serum $\mathrm{E}_{2}$ levels at 8 weeks gestation were negatively correlated with offspring birth weight ( $r=$ $-0.32, P<0.05$, Fig. 1B), suggesting that offspring birth weight could be inversely affected by increasing maternal serum $\mathrm{E}_{2}$ levels.

\section{CDKN1C and DNMT1 Expression in Embryo Tissue, Newborn UCBMNC, and Placenta}

qRT-PCR was performed on 77 early embryo tissues from selective MFPR and 29 embryo tissues from naturally conceived singleton pregnancies to investigate the mRNA levels of imprinted genes related to growth and development in multiple and singleton embryo tissue. The results showed that $C D K N 1 C$ mRNA levels were significantly higher in early embryo tissue from triplet and quadruplet pregnancies 


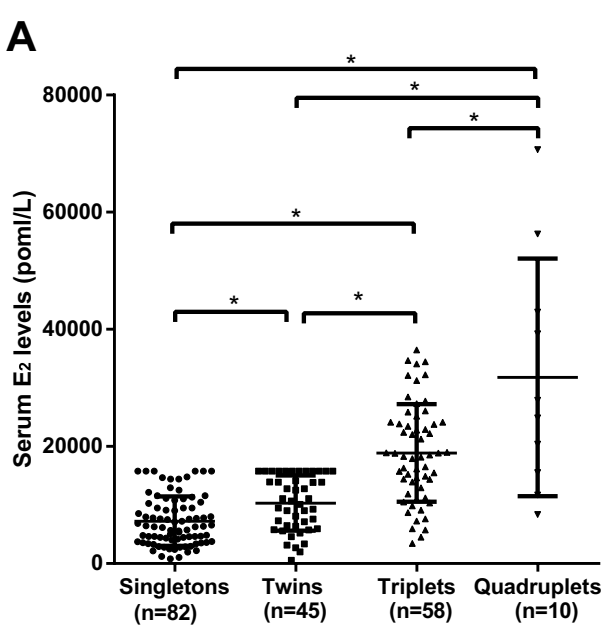

Fig. 1 (A) Maternal serum $\mathrm{E}_{2}$ levels were significantly elevated at 8 weeks of gestation with an increasing number of fetuses. $E_{2}$ levels were determined by electrochemiluminescence. $\mathrm{E}_{2}$ levels in serum samples from women with singleton pregnancy $(n=82)$, twin pregnancy $(n=45)$, triplet pregnancy $(n=58)$, or quadruplet pregnancy

than those in singleton pregnancies. The CDKNIC mRNA levels in embryo tissue from quadruplet pregnancies were also higher than those in triplet pregnancy embryo tissue; however, the difference was not significant. We further analyzed $C D K N 1 C$ expression levels in newborn UCBMNC and placenta of 20 multiple pregnancies reduced to twins and matched primary twin pregnancies. Consistent with the results from the embryo tissue, CDKNIC expression levels in the UCBMNC and placenta from multiple pregnancies reduced to twins were significantly increased compared to those from the matched twin pregnancies (Fig. 2A). Significantly higher $D N M T 1$ expression levels were also observed in MFPR embryo tissue, UCBMNC, and placenta from multiple pregnancies reduced to twins compared to the controls (Fig. 2B).

\section{$E_{2}$ Modulates the Expression of DNMT1 and CDKN1C mRNA Levels}

We found that serum $E_{2}$ levels were significantly higher in multiple pregnancies than those in singleton pregnancies and were elevated with the increasing numbers of fetuses. To investigate whether $\mathrm{E}_{2}$ could regulate $C D K N I C$ and $D N M T 1$ mRNA levels, HTR-8 cells were treated with $\mathrm{E}_{2}$ and the ER inhibitor ICI182780. Treatment of estrogen-starved HTR8 cells with $\mathrm{E}_{2}$ for $24 \mathrm{~h}$ increased CDKNIC and DNMT1 mRNA levels in a dose-dependent manner. However, incubation with ICI182780 significantly reduced the effects of $\mathrm{E}_{2}$ on CDKN1C and DNMT1 mRNA expression (Fig. 3A and B). We next investigated the effect of DNMT1 on CDKN1C expression. As shown in Fig. 3C, DNMT1 siRNA effectively
B

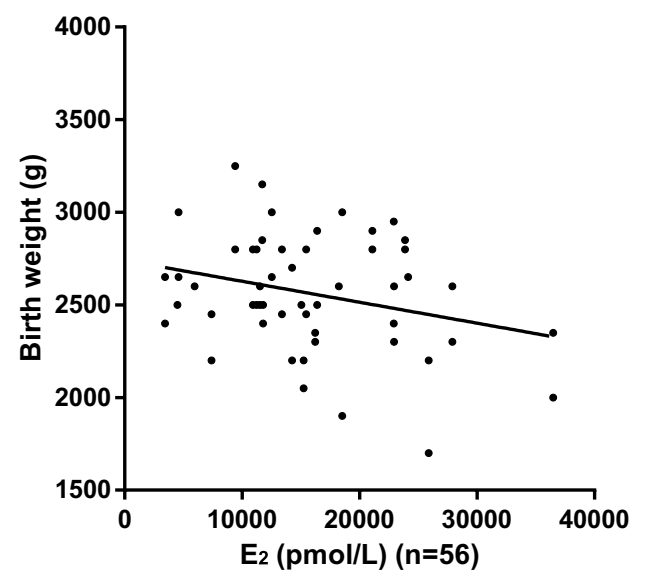

$(n=10)$ were compared by one-way ANOVA $(* P<0.05)$. (B) Multivariate correlation analysis showed that maternal serum $\mathrm{E}_{2}$ levels were inversely correlated with the birth weight of offspring $(n=56$, $\mathrm{r}=-0.32, * P<0.05)$

knocked down $D N M T 1$ expression. Notably, DNMT1 knockdown reversed the $\mathrm{E}_{2}$-induced increase in $C D K N 1 C$ mRNA levels, indicating that $D N M T 1$ mediates $\mathrm{E}_{2}$-induced upregulation of $C D K N 1 C$ (Fig. 3D).

\section{KvDMR1 Hypermethylation Mediates $\mathrm{E}_{2}$-Induced CDKN1C Upregulation}

We examined the methylation status of $K v D M R I$ in embryo tissue, UCBMNC, and placenta using MSP. We found that $K v D M R l$ was hypermethylated in MFPR embryo tissues, UCBMNC, and placenta for multiple pregnancies reduced to twins (Fig. 4A). These results were further confirmed using bisulfite DNA sequencing (Fig. 4B). Furthermore, treatment of HTR8 cells with $\mathrm{E}_{2}$ led to $K v D M R 1$ hypermethylation (Fig. 4C). Together, these results suggested that CDKNIC upregulation was associated with the increased methylation of $K v D M R 1$.

\section{DNMT1 Promoter Responses to $\mathrm{E}_{\mathbf{2}}$ and Its Receptors}

$E_{2}$ is thought to exert its biological effects by binding to ERs [34]. To investigate if the regulation of DNMT1 expression by $E_{2}$ is at the promoter level, we determined the effect of $E_{2}$ stimulation on the activation of a luciferase reporter driven by the proximal 2.4-kb fragment of the DNMT1 promoter. As shown in Fig. 5, $\mathrm{E}_{2}$ induced a DNMTl-luc activity fivefold compared to the control. Three putative estrogen response elements (EREs) were located in the DNMT1 promoter using the transcription factor binding sites and cis-regulatory search system (http://rsat.ulb.ac.be/). Furthermore, 
A
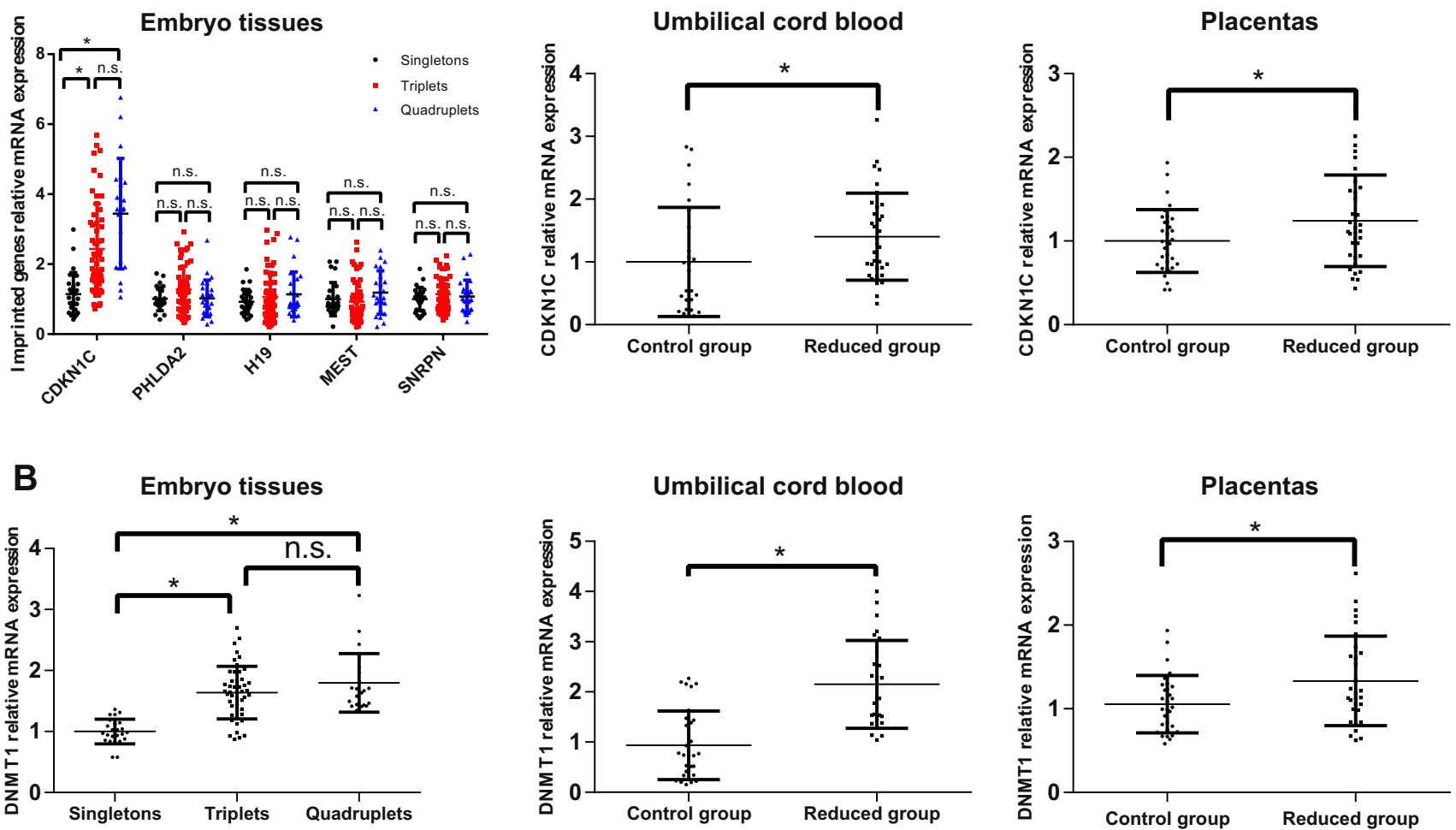

Fig. 2 (A) Relative expression of imprinted genes in embryo tissues and CDKNIC in newborn UCBMNC and placenta tissues. (B) Relative $D N M T 1$ expression in embryo tissues, UCBMNC, and placenta tissues

CHIP demonstrated that ER $\alpha$ could bind to the DNMT1 promoter in HTR8 cells after treatment with $\mathrm{E}_{2}$ (Fig. 5). In particular, ER $\alpha$ bound to the ERE-like site at -659 bp of the $D N M T 1$ promoter. Collectively, these findings indicate that $D N M T 1$ was the downstream target of $\mathrm{E}_{2}$.

\section{Discussion}

Many studies have shown that MFPR is associated with a reduced risk of preterm birth, LBW, and no increase in pregnancy loss compared to that in unreduced multiple pregnancies [28, 35-37]. The perinatal outcomes of twin pregnancies after early and late MFPR appear similar [38]. MFPR has been widely accepted as a legitimate treatment option for patients with triplets or higher-order pregnancies [36]. However, these previous studies all compared obstetric outcomes before and after MFPR. To date, only three studies have compared reduced and unreduced multiple pregnancies. Mheen et al. [39] reported that the median neonatal birth weight in multiple pregnancies reduced to singleton pregnancies was significantly lower than that in primary singleton pregnancies. Razaz et al. [37] found that the rate of very low birth weight was significantly higher among pregnancies reduced to twins than unreduced twin pregnancies. Zipori et al. [40] found that the incidence of SGA was not different between the MFPR and unreduced triplet groups. Our findings are consistent with these results. In the current study, we found an increased risk of LBW and SGA when maternal serum $\mathrm{E}_{2}$ levels were high in the first trimester of multiple pregnancies. Although the results for pregnancies reduced to singletons were better than those reduced to twins, the mean birth weight of pregnancies reduced to singletons was still significantly lower than that of primary singletons. When we excluded the effects of the duration of gestation, there was a higher incidence rate of SGA in multiple pregnancies reduced to singletons and twins. These results indicate that some effects of the first trimester of multiple pregnancies persist and cannot be completely eliminated by fetal reduction.

Maternal serum $\mathrm{E}_{2}$ levels in the first trimester of pregnancy were increased with the number of fetuses and negatively correlated with offspring birth weight. $E_{2}$ is the most bioactive estrogen. In mice, high E2 exposure during early pregnancy decreases offspring body weight [41]. Moreover, high $\mathrm{E}_{2}$ doses cause embryonic mortality and fetal and placental growth retardation in rats [42]. However, the mechanisms by which the dramatic increase in $\mathrm{E}_{2}$ levels in pregnant women adversely affects fetal development and 

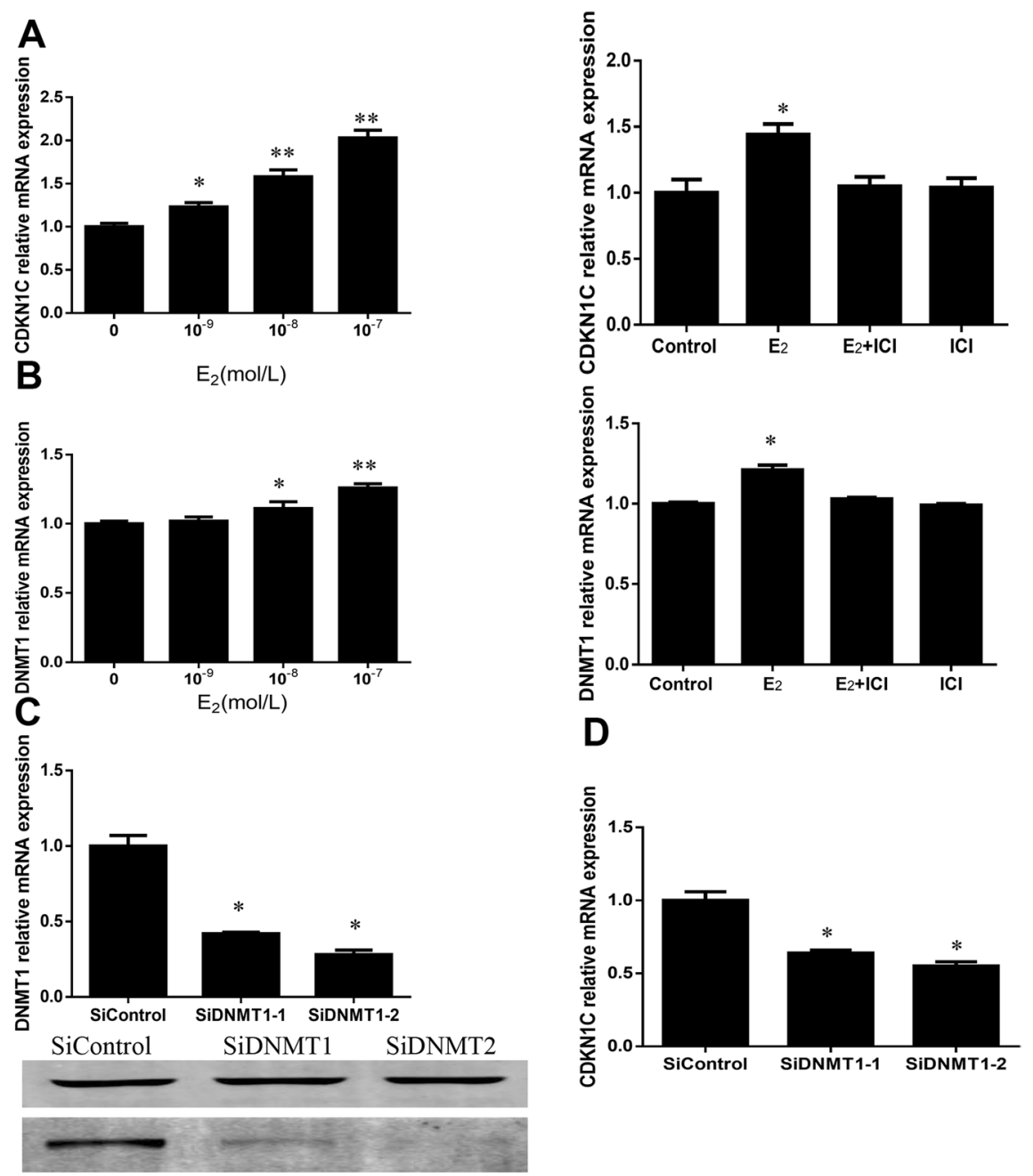

Fig. $3 \mathrm{E}_{2}$ increased $C D K N 1 C$ and $D N M T 1$ expression in a dosedependent manner. These effects were attenuated by ICI, an ER antagonist. (A) CDKN1C expression in HTR-8 cells after treatment with different doses of $\mathrm{E}_{2}$ for $24 \mathrm{~h}$. The increased CDN1C mRNA expression levels induced by $\mathrm{E}_{2}$ were blocked by the estrogen blocker ICI182780 $\left(10^{-7} \mathrm{~mol} / \mathrm{L}\right)$ or co-treatment with $\mathrm{E}_{2}$ and ER antagonist ICI $\left(10^{-7} \mathrm{~mol} / \mathrm{L}\right)(n=9)$. (B) DNMT1 expression in HTR-8 cells after treatment with different doses of $\mathrm{E}_{2}$ for $24 \mathrm{~h}$. The increased DNMT1 mRNA expression levels induced by $\mathrm{E}_{2}$ were blocked by ICI

growth during the first trimester of multiple pregnancies are unknown.

Evidence from animals and humans has indicated that certain transient environmental influences can produce persistent changes in epigenetic marks that last throughout life [14]. Imprinted genes are implicated in the regulation of fetal growth and development and are especially sensitive to environment-mediated changes in DNA methylation [43]. Endocrine disruptors can alter DNA methylation patterns of key genes, resulting in transcriptional changes [44]. Cases of ART-conceived children afflicted with imprinting mutations have been reported [45]. CDKNIC is a maternally expressed imprinted gene with a major role in regulating embryonic $\left(10^{-7} \mathrm{~mol} / \mathrm{L}\right)(n=9)$. Effects of DNMT1 silencing on the expression of DNMT1 and response to $\mathrm{E}_{2}$ induction in HTR8 cells, C and D. (C) HTR8 cells were transiently transfected with DNMT1 or scrambled control siRNA. Forty-eight hours after transfection, cell samples were analyzed by qRT-PCR and western blotting. (D) HTR8 cells were transiently transfected with siRNA against DNMT1 and then incubated with $10^{-7} \mathrm{M} \mathrm{E}_{2}$. CDKN1C expression was analyzed by qRTPCR. DNMT1 knockdown decreased the responsiveness of HTR8 cells to $\mathrm{E}_{2}$ stimulation

growth. Previous studies demonstrated that excess CDKN1C could cause embryonic growth retardation in animals and humans $[46,47]$. In the present study, we found that the expression levels of $C D K N 1 C$ and DNTMI were significantly upregulated in embryo tissue from multiple pregnancies compared to singleton pregnancies.

The expression of imprinted genes is regulated by the methylation status of the CpGs in the differentially methylated regions (DMRs) of each gene [48]. DNMTs are responsible for DNA methylation, and high DNMT1 activity contributes to abnormal hypermethylation of certain genes [15]. These observations suggest that $E_{2}$ might interact with $D N M T 1$ and positively regulate its enzymatic 

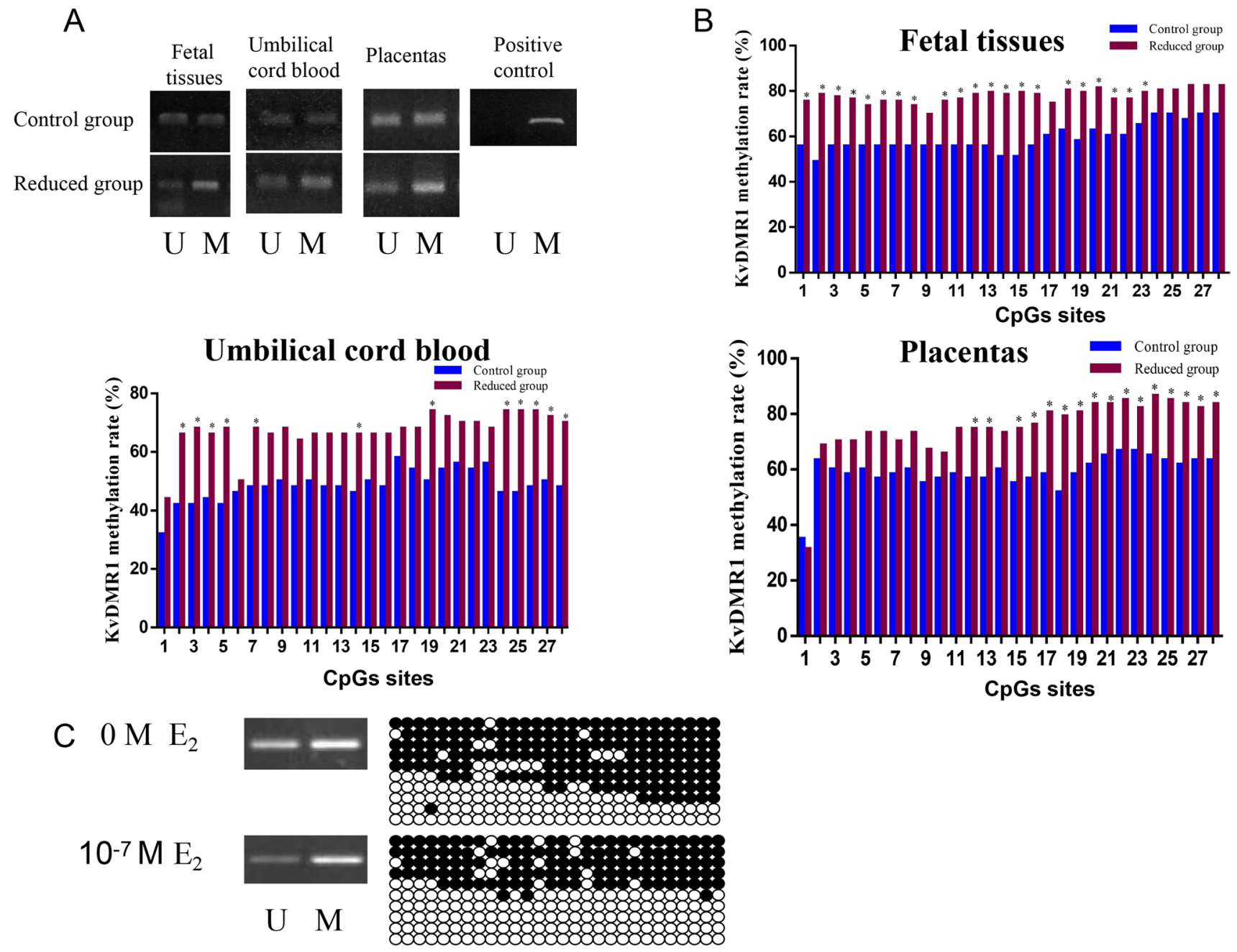

Fig. 4 (A) Representative MSP results of DNA methylation. KvDMR1 was hypermethylated in MFPR embryo tissue, UCBMNC, and placenta of multiple pregnancies reduced to twins. (B) KvDMRI CpGs had significantly higher hypermethylation in embryo tissues of multiple pregnancies, UCBMNC, and placenta of multiple pregnancies reduced to twins, with $75.00 \%$ (21/28), $42.86 \%(12 / 28)$, and $57.14 \%(16 / 28)$ of the CpGs showing abnormal hypermethylation,

activity. $D N M T 1$ overexpression leads to hypermethylation of KvDMRI. KvDMRI is the predominant imprinting control region of $C D K N 1 C$ on human chromosome $11 \mathrm{p} 15$. We found that the methylation levels of KvDMRI and the DMR of $C D K N 1 C$ are significantly increased in response to $\mathrm{E}_{2}$, resulting in the $C D K N 1 C$ upregulation. This upregulation could contribute to the LBW and SGA of multiple pregnancies. Moreover, increased CDKNIC and DNMTI expression levels were also associated with the hypermethylation of $K v D M R 1$ in UCBMNC and placenta of multiple pregnancies reduced to twin pairs, indicating that transiently high serum $\mathrm{E}_{2}$ levels might induce persistent changes in epigenetic marks during early gestation. respectively. (C) MSP and bisulfite sequencing analysis of KvDMRI methylation in HTR8 cells without or with $10^{-7} \mathrm{M} \mathrm{E}_{2}$ treatment. Ten independent clones of the indicated groups were sequenced. Black circles denote methylated cytosine in specific $\mathrm{CpGs}$, and white circles denote nonmethylated cytosine in specific CpGs. $\mathrm{U}$ and $\mathrm{M}$ denote unmethylated DNA-specific and methylated DNA-specific amplification, respectively. $\mathrm{P}$ denotes the positive control

To confirm that $C D K N I C$ expression was regulated by high $\mathrm{E}_{2}$ levels, we further investigated the regulation of CDKNIC expression by $\mathrm{E}_{2}$. In the "classical" mechanism of estrogen action, the long-term effects of $\mathrm{E}_{2}$ are generally ascribed to transcriptional modulation of target genes through the binding of estrogen receptors (ERs). These receptors modulate gene expression directly through EREs in the promoter regions of target genes or indirectly through interaction with transcription factors, co-activators, or transcription complexes [49, 50]. Using a reporter gene assay, we demonstrated that ER $\alpha$ activated DNMT1 transcription through an ERE located at $-659 \mathrm{bp}$ upstream of the transcriptional starting site. The 


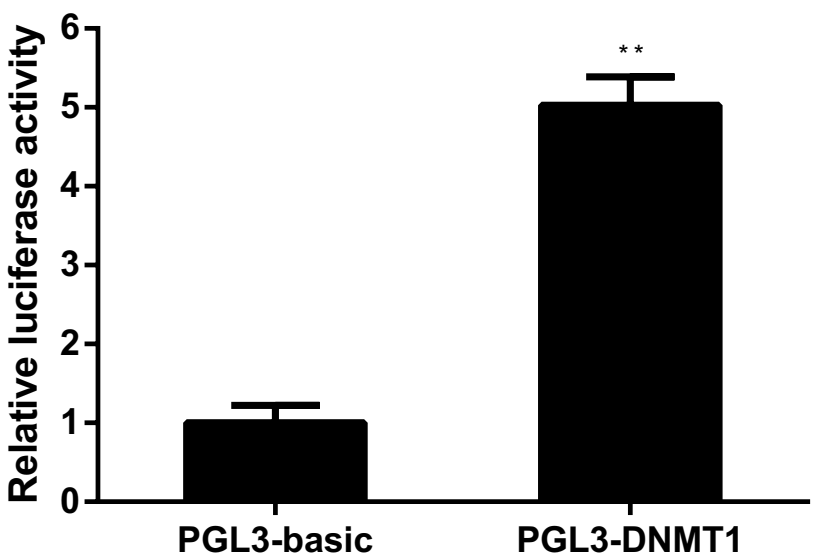

Fig. 5 (A) $\mathrm{E}_{2}$ induced human DNMT1 transcription through an ERE proximal to the transcription start site. HTR8 cells cultured in phenol red-free medium supplemented with 5\% double-charcoal stripped FCS and transiently transfected with empty pGL3-basic or pGL3DNMT1 $(1 \mu \mathrm{g})$ with the treatment of $\mathrm{E}_{2}$. Cells were harvested $24 \mathrm{~h}$ after transfection and assayed for luciferase activity. DNMT1 promoter-mediated luciferase values were normalized to control Renilla luciferase values. (B) ER $\alpha$ binds directly to the ERE on the DNMT1 promoter. ChIP analysis of the human DNMT1 promoter was performed after HTR8 cells were treated with $\mathrm{E}_{2}$ for $24 \mathrm{~h}$. ChIP assays were performed using IgG, anti-RNA polymerase, and anti-ER $\alpha$ antibodies as indicated. After cross-link reversal, the co-immunoprecipitated DNA was amplified by PCR using primers specific for the DNMT1 ERE containing region ( -659 to -647$)$ or a control region $(-2123$ to -2111 or -728 to -716$)$. The PCR products were resolved using a $2 \%$ agarose gel. Representative data from three independent experiments are presented

\section{Conclusions}

The present study demonstrated that high maternal $\mathrm{E}_{2}$ levels might induce high $C D K N 1 \mathrm{C}$ expression, leading to LBW and SGA in the first trimester of multiple pregnancies. To minimize the risks of LBW and SGA, abnormally high maternal serum $\mathrm{E}_{2}$ levels during early pregnancy in ART patients should be avoided.

Supplementary Information The online version contains supplementary material available at https://doi.org/10.1007/s43032-021-00735-8.

Acknowledgements We thank Dr. Charles H. Graham (Department of Anatomy and Cell Biology, Queen's University at Kingston, Ontario, Canada) for his kind gift of the HTR8/SVneo cell line.

Author Contribution Formal analysis, Ning-ning Hou and Meng Ye. Methodology, Xiao-Ling Hu, Ai-Xia Liu, and Yi-Min Zhu. Project administration, Xiao-Ling Hu and Shuai Shi. Resources, Jing-Yi Li; Supervision, Yi-Min Zhu, and He-Feng Huang. Validation, Miao Li. Writing (original draft), Xiao-Ling Hu and Yong-Chao Lu. Writing (review and editing), Jian-Zhong Sheng and He-Feng Huang.

Funding The work was supported by the National Natural Science Foundation of China (No. 81803245); the Major Program of National Natural Science Foundation of China (No. 81490742); National Key Research and Development Program of China (No. 2017YFC1001301 and 2018YFC1003200); International Cooperation Project of China and Canada NSFC (No. 81661128010).

Data Availability All raw data and material are available upon request.

Code Availability Not applicable.

\section{Declarations}

Ethics Approval The study was conducted with the approval of the Ethics Committee from the Women's Hospital, School of Medicine, Zhejiang University, No. 20130031, 27 June 2013.

Consent to Participate All subjects consented to the sample retrieval as well as collection of clinical information as approved by the Ethics Committee in Women' Hospital, School of Medicine, Zhejiang University.

Consent for Publication All the authors consent to the publication of this paper.

Conflict of Interest The authors declare no competing interests.

Open Access This article is licensed under a Creative Commons Attribution 4.0 International License, which permits use, sharing, adaptation, distribution and reproduction in any medium or format, as long as you give appropriate credit to the original author(s) and the source, provide a link to the Creative Commons licence, and indicate if changes were made. The images or other third party material in this article are included in the article's Creative Commons licence, unless indicated otherwise in a credit line to the material. If material is not included in the article's Creative Commons licence and your intended use is not permitted by statutory regulation or exceeds the permitted use, you will 
need to obtain permission directly from the copyright holder. To view a copy of this licence, visit http://creativecommons.org/licenses/by/4.0/.

\section{References}

1. Calkins K, Devaskar SU. Fetal origins of adult disease. Curr Probl Pediatr Adolesc Health Care. 2011;41(6):158-76.

2. Barker DJ. The developmental origins of adult disease. J Am Coll Nutr. 2004;23(6 Suppl):588S-595S.

3. Sutcliffe AG, Ludwig M. Outcome of assisted reproduction. Lancet Lancet. 2007;370(9584):351-9.

4. Hall JG. Twinning Lancet. 2003;362:735-43.

5. Esteves-Pereira AP, da Cunha AJLA, Nakamura-Pereira M, Moreira ME, Domingues RMSM, Viellas EF, et al. Twin pregnancy and perinatal outcomes: data from 'Birth in Brazil Study.' PLoS One. 2021;16(1):e0245152.

6. Muhlhausler BS, Hancock SN, Bloomfield FH, Harding R. Are twins growth restricted? Pediatr Res. 2011;70(2):117-227.

7. Guo L, Choufani S, Ferreira J, Smith A, Chitayat D, Shuman C, et al. Altered gene expression and methylation of the human chromosome 11 imprinted region in small for gestational age (SGA) placentae. Dev Biol. 2008;320(1):79-91.

8. Berntsen S, Söderström-Anttila V, Wennerholm UB, Laivuori H, Loft A, Oldereid NB, et al. The health of children conceived by ART: 'the chicken or the egg?' Hum Reprod Update. 2019;25(2):137-58.

9. Nilsson PM, Viigimaa M, Giwercman A, Cifkova R. Hypertension and reproduction. Curr Hypertens Rep. 2020;22(4):29.

10. Shang Y, Hu X, DiRenzo J, Lazar MA, Brown M. Cofactor dynamics and sufficiency in estrogen receptor-regulated transcription. Cell. 2000;103(6):843-52.

11. Hart RJ, Doherty DA, Keelan JA, McLachlan R, Skakkebaek NE, Norman RJ, et al. Early life events predict adult testicular function; data derived from the Western Australian (Raine) birth cohort. J Clin Endocrinol Metab. 2016;101(9):3333-44.

12. de Assis S, Warri A, Cruz MI, Laja O, Tian Y, Zhang B, et al. High-fat or ethinyl-oestradiol intake during pregnancy increases mammary cancer risk in several generations of offspring. Nat Commun. 2012;3:1053

13. $\mathrm{Hu} \mathrm{XL}$, Feng $\mathrm{C}$, Lin $\mathrm{XH}$, Zhong ZX, Zhu YM, Lv PP, et al. Huang, High maternal serum estradiol environment in the first trimester is associated with the increased risk of small-for-gestational-age birth. J Clin Endocrinol Metab. 2014;99(6):2217-24.

14. Heijmans BT, Tobi EW, Stein AD, Putter H, Blauw GJ, Susser ES, et al. Persistent epigenetic differences associated with prenatal exposure to famine in humans. Proc Natl Acad Sci U S A. 2008;105(44):17046-9.

15. Bale TL. Epigenetic and transgenerational reprogramming of brain development. Nat Rev Neurosci. 2015;16(6):332-44.

16. Lee CF, Ou DS, Lee SB, Chang LH, Lin RK, Li YS, et al. hNaa10p contributes to tumorigenesis by facilitating DNMT1mediated tumor suppressor gene silencing. J Clin Invest. 2010;120(8):2920-30.

17. Hao X, Luo H, Krawczyk M, Wei W, Wang W, Wang J, et al. DNA methylation markers for diagnosis and prognosis of common cancers. Proc Natl Acad Sci U S A. 2017;114(28):7414-9.

18. Xu Q, Jiang Y, Yin Y, Li Q, He J, Jing Y, et al. A regulatory circuit of miR-148a/152 and DNMT1 in modulating cell transformation and tumor angiogenesis through IGF-IR and IRS1. J Mol Cell Biol. 2013;5(1):3-13.
19. Nabilsi NH, Broaddus RR, Loose DS. DNA methylation inhibits p53-mediated survivin repression. Oncogene. 2009;28(19):2046-50.

20. He XJ, Chen T, Zhu JK. Regulation and function of DNA methylation in plants and animals. Cell Res. 2011;21(3):442-65.

21 Constância M, Hemberger M, Hughes J, Dean W, Ferguson-Smith A, Fundele R, et al. Placental-specific IGF-II is a major modulator of placental and fetal growth. Nature. 2002;417(6892):945-8.

22. Mancini-Dinardo D, Steele SJ, Levorse JM, Ingram RS, Tilghman SM. Elongation of the Kcnq1ot1 transcript is required for genomic imprinting of neighboring genes. Genes Dev. 2006;20(10):1268-82.

23. Maher ER, Reik W. Beckwith-Wiedemann syndrome: imprinting in clusters revisited. J Clin Invest. 2000;105(3):247-52.

24. Egger G, Liang G, Aparicio A, Jones PA. Epigenetics in human disease and prospects for epigenetic therapy. Nature. 2004;429(6990):457-63.

25. Kanber D, Buiting K, Zeschnigk M, Ludwig M, Horsthemke B. Low frequency of imprinting defects in ICSI children born small for gestational age. Eur J Hum Genet. 2009;17(1):22-9.

26. Shin JY, Fitzpatrick GV, Higgins MJ. Two distinct mechanisms of silencing by the KvDMR1 imprinting control region. EMBO J. 2008;27(1):168-78.

27. Diaz-Meyer N, Day CD, Khatod K, Maher ER, Cooper W, Reik $\mathrm{W}$, et al. Silencing of CDKN1C (p57KIP2) is associated with hypomethylation at KvDMR1 in Beckwith-Wiedemann syndrome. J Med Genet. 2003;40(11):797-801.

28. Antsaklis A, Anastasakis E. Selective reduction in twins and multiple pregnancies. J Perinat Med. 2011;39(1):15-21.

29. Ulmer AJ, Scholz W, Ernst M, Brandt E, Flad HD. Isolation and subfractionation of human peripheral blood mononuclear cells (PBMC) by density gradient centrifugation on Percoll. Immunobiology. 1984;166(3):238-50.

30. Graham CH, Hawley TS, Hawley RG, MacDougall JR, Kerbel RS, Khoo N, et al. Establishment and characterization of first trimester human trophoblast cells with extended lifespan. Exp Cell Res. 1993;206(2):204-11.

31. Ding GL, Wang FF, Shu J, Tian S, Jiang Y, Zhang D, et al. Transgenerational glucose intolerance with Igf2/H19 epigenetic alterations in mouse islet induced by intrauterine hyperglycemia. Diabetes. 2012;61(5):1133-42.

32. Zhu H, Chen B, Cheng Y, Zhou Y, Yan YS, Luo Q, et al. Insulin therapy for gestational diabetes mellitus does not fully protect offspring from diet-induced metabolic disorders. Diabetes. 2019;68(4):696-708.

33. Wang F, Pan J, Liu Y, Meng Q, Lv P, Qu F, et al. Alternative splicing of the androgen receptor in polycystic ovary syndrome. Proc Natl Acad Sci U S A. 2015;112(15):4743-8.

34. Shang Y. Molecular mechanisms of oestrogen and SERMs in endometrial carcinogenesis. Nat Rev Cancer. 2006;6(5):360-8.

35. Haas J, Mohr Sasson A, Barzilay E, Mazaki Tovi S, Orvieto $\mathrm{R}$, Weisz $\mathrm{B}$, et al. Perinatal outcome after fetal reduction from twin to singleton: to reduce or not to reduce? Fertil Steril. 2015;103(2):428-32.

36. Drugan A, Weissman A. Multi-fetal pregnancy reduction (MFPR) to twins or singleton - medical justification and ethical slippery slope. J Perinat Med. 2017;45(2):181-4.

37. Razaz N, Avitan T, Ting J, Pressey T, Joseph KS. Perinatal outcomes in multifetal pregnancy following fetal reduction. CMAJ. 2017;189(18):E652-8.

38. Haas J, Barzilay E, Hourvitz A, Dor J, Lipitz S, Yinon Y, et al. Outcome of early versus late multifetal pregnancy reduction. Reprod Biomed Online. 2016;33(5):629-34.

39. van de Mheen L, Everwijn SM, Knapen MF, Haak MC, Engels MA, Manten GT, et al. Pregnancy outcome after fetal reduction 
in women with a dichorionic twin pregnancy. Hum Reprod. 2015;30(8):1807-12.

40. Zipori Y, Haas J, Berger H, Barzilay E. Multifetal pregnancy reduction of triplets to twins compared with nonreduced triplets: a meta-analysis. Reprod Biomed Online. 2017;35(3):296-304.

41. Jin M, Lv PP, Yu TT, Shen JM, Feng C, Huang HF. IGFBP1 involved in the decreased birth weight due to fetal high estrogen exposure in mice. Biol Reprod. 2016;95(5):96.

42. Bartholomeusz RK, Bruce NW, Lynch AM. Embryo survival, and fetal and placental growth following elevation of maternal estradiol blood concentrations in the rat. Biol Reprod. 1999;61(1):46-50.

43. Ollikainen M, Smith KR, Joo EJ, Ng HK, Andronikos R, Novakovic $\mathrm{B}$, et al. DNA methylation analysis of multiple tissues from newborn twins reveals both genetic and intrauterine components to variation in the human neonatal epigenome. Hum Mol Genet. 2010;19(21):4176-88.

44. Ke ZH, Pan JX, Jin LY, Xu HY, Yu TT, Ullah K, et al. Bisphenol A exposure may induce hepatic lipid accumulation via reprogramming the DNA methylation patterns of genes involved in lipid metabolism. Sci Rep. 2016;6:31331.

45 Maher ER. Imprinting and assisted reproductive technology. Hum Mol Genet. 2005;14(Spec No 1):R133-8.
46. Andrews SC, Wood MD, Tunster SJ, Barton SC, Surani MA, John RM. Cdkn1c (p57Kip2) is the major regulator of embryonic growth within its imprinted domain on mouse distal chromosome 7. BMC Dev Biol. 2007;7:53.

47. Schonherr N, Meyer E, Roos A, Schmidt A, Wollmann HA, Eggermann T. The centromeric 11p15 imprinting centre is also involved in Silver-Russell syndrome. J Med Genet. 2007;44(1):59-63.

48. Messerschmidt DM, de Vries W, Ito M, Solter D, FergusonSmith A, Knowles BB. Trim28 is required for epigenetic stability during mouse oocyte to embryo transition. Science. 2012;335(6075):1499-502.

49. Hodgin JB, Krege JH, Reddick RL, Korach KS, Smithies O, Maeda N. Estrogen receptor alpha is a major mediator of 17betaestradiol's atheroprotective effects on lesion size in Apoe-/- mice. J Clin Invest. 2001;107(3):333-40.

50. Deroo BJ, Korach KS. Estrogen receptors and human disease. J Clin Invest. 2006;116(3):561-70.

51. Klein-Hitpass L, Schorpp M, Wagner U, Ryffel GU. An estrogenresponsive element derived from the 5' flanking region of the Xenopus vitellogenin A2 gene functions in transfected human cells. Cell. 1986;46(7):1053-61. 